Review Article

\title{
Distribution of Seismic Damage in Steel Buildings Component Equipped by Viscoelastic Dampers against Far-Field Earthquake
}

\author{
Yaser Parvin Darabad $\left(D,{ }^{1}\right.$ Alireza Hassanpour Yasaghi, ${ }^{2}$ Beniamin Khodaei, ${ }^{3}$ \\ and Reza Zarei ${ }^{4}$ \\ ${ }^{1}$ Sharif University of Technology, International Campus, Kish Island, Iran \\ ${ }^{2}$ Department of Civil Engineering, Islamic Azad University, Mashhad, Iran \\ ${ }^{3}$ Department of Civil Engineering, Yazd Branch, Islamic Azad University, Yazd, Iran \\ ${ }^{4}$ Department of Civil Engineering, Academic Center of Education-Culture-Research, Khouzestan Branch, Ahwaz, Iran
}

Correspondence should be addressed to Yaser Parvin Darabad; yaserparvin@yahoo.com

Received 13 June 2021; Revised 24 June 2021; Accepted 20 July 2021; Published 4 August 2021

Academic Editor: S. Mahdi S. Kolbadi

Copyright ( $\odot 2021$ Yaser Parvin Darabad et al. This is an open access article distributed under the Creative Commons Attribution License, which permits unrestricted use, distribution, and reproduction in any medium, provided the original work is properly cited.

\begin{abstract}
Damage to structures with the concept of inelastic behavior and consequently hysteresis energy is very close. Therefore, it can be said that hysteresis energy at these levels can be a significant criterion for designing or controlling the structure. In this research, the first three steel frames of 4, 8 , and 12 floors with the medium bending frame system have been designed with the statically equivalent method according to valid international regulations; then, all frames have been subjected to nonlinear dynamic analysis by seven accelerometers. The purpose of this study is to investigate the distribution of damage, energy, relative displacement, roof displacement, and base shear in the studied frames. In the following, the necessity of using the retrofitting method to reduce the relative displacement is described based on the regulations. Then, viscoelastic dampers are used to strengthen and reduce damage in the studied frames in the face of distant field records. The obtained results indicate that despite the uniform distribution of resistance in the height of the floors, the hysteresis energy distribution and damage diagrams do not follow this distribution and other parameters such as hysteresis energy, which play a major role in structural members' damage, should be included in the design process. In this research, viscoelastic dampers have been used for retrofitting. The results show that this type of damper shows good performance in reducing damage under earthquakes in the remote area.
\end{abstract}

\section{Introduction}

On average, 10,000 people annually suffer from earthquakes in the world. The studies performed by UNESCO indicate that the financial damage caused by the earthquake during 1926-1950 was about \$ 10 billion. During this time, two cities and 200 villages were destroyed in Central Asia [1]. Since then, several cities have been established, consisting of Ashgabat (1948), Aqdir (1960), Escopé (1963), Managua (1972), Gamona and Tangshan (1976), Mexico City (1985), and Spitaka (1988). Kobe (1995), cities in Turkey and Taiwan (1999), and hundreds of villages were razed to the ground by earthquakes [2]. The historical writings witness the human's long-standing concern about the dangers of earthquakes [3].
That is why man is trying to deal with this natural phenomenon, in which he has made significant progress [4]. However, he has still not been able to achieve complete safety and security, both physically and materially, due to the extreme complexity of such phenomenon [5]. When an earthquake occurs, a lot of energy enters the structure, and it should absorb or lose this energy in different ways [6]. The members of the structure enter the inelastic range against the seismic energy, which is a considerable amount, so that they can absorb this energy through changing their deformations [7]. When the members of the structures enter the inelastic range, permanent deformations occur in the structure, which it is necessary to replace or strengthen those members that are too deformed or can no longer be used with new 
members, which is difficult to do and the cost is high [8]. Therefore, as the dampers are placed in the structure, these dampers prevent other structural components from entering the inelastic range through absorbing seismic energy [9]. Thus, the various components of the structure still retain their usability after the earthquake and they can only be replaced or repaired by visiting the dampers if necessary [10].

Using the viscoelastic materials in vibration control dates back to the 1950s, when Ross et al. used them in the aerospace industry to control vibrations and prevent fatigue in aircraft fuselages [11]. However, it was first used in civil engineering in 1969, when 10,000 viscoelastic dampers were used in the twin towers of world trade to withstand the wind [12]. Then, 260 viscoelastic dampers were used in the 73story Columbia structure in the United States in 1982, and 16 viscoelastic dampers in the 60-story structure were used to resist wind vibrations in 1988. Further, it is used in the roof of the China-Tom railway station in Tapie, Taiwan in 1994, and the Torishima Tower in Japan in 1999 [13, 14]. In 1991, Zhang and Song installed three types of viscoelastic dampers with different specifications in a five-story steel building and investigated the factors affecting the performance of viscoelastic dampers through seismic table tests, such as temperature and frequency [15]. They found that these types of dampers have a great impact on reducing structural responses at all levels [16]. In 2003, Madsen et al. conducted some studies on viscoelastic dampers, indicating that first the performance of dampers changes in the face of various earthquakes, leading to the different frequency content of earthquakes; and second, the viscoelastic dampers perform better in the lower floors, where it is closest to the input energy source [17].

In 2003, Tezkan and Uluca performed some parametric studies on models of steel structures with a different number of floors and openings and evaluated the impact of the amount of additional damping to the structure through viscoelastic dampers, as well as the frequency content of earthquake stagnation on the performance of this type of dampers [18]. In addition, they proposed an optimal distribution pattern of dampers at the height of the structure [19]. In 2004, Min examined 18 types of building frames with different heights and with lateral bearing systems of bending frame, bracing frame, and hybrid frame and investigated the effect of using viscoelastic dampers in reducing the seismic responses of structures, such as the displacement of the top floor and the force created in the members [20]. In 2006, Graham and Powell investigated the irregular three-dimensional models of structures and evaluated the performance of viscoelastic dampers in reducing seismic responses by considering the effect of soil-structure interaction [21].

\section{Material and Methods}

2.1. Energy Equations in a MDOF with Nonlinear Behavior. The inelastic behavior increases the effective natural cycle period or decreases the frequency of the structure and the damping ratio of the structure [22]. Considering the fundamental energy equation in free multidegree systems, the differences between elastic and inelastic analysis can be found in

$$
[m]\{\ddot{u}(t)\}+[c]\{\dot{u}(t)\}+[k]\{u(t)\}=-[m]\left\{\ddot{u}_{g}(t)\right\} .
$$

All dynamic properties, including stiffness, mass, and damping of the system, remain constant and unchanged during excitation in the elastic linear state [23]. However, the dynamic properties of the structure undergo some changes through passing this area and entering the inelastic area [24]. That is, they can be considered as a variable function of time [25]. In conventional structures, the amount of mass alone does not change during the response as shown in

$$
[m]\{\ddot{u}(t)\}+[c(t)]\{\dot{u}(t)\}+[k(t)]\{u(t)\}=-[m]\left\{\ddot{u}_{g}(t)\right\},
$$

where the hardness and damping parameters are timevarying functions [26]. Thus, the values of such quantities should be used at all times instead of using constant values of hardness and damping $[11,27]$. Akiyama found that $E_{I}^{\prime}$ in the system of one degree of freedom is a very good estimate of the energy entering the multistory building with a natural frequency equal to the frequency of the system of one degree of freedom [28]. Although no parametric study has been performed to investigate such a relationship with the absolute input energy, the results of the vibrating table test on a 6-story steel structure with concentric bracing confirm the existence of such a relationship [29]. In damage assessment, it is important to find a clear and measurable quantity to provide the amount of damage that the structure suffers from [30]. During the last 20 to 30 years, significant amounts of research have been conducted to improve and increase the accuracy of damage assessment methods [31].

The force created in this system is due to stiffness and damping [32]. The part related to the hardness is the product of the stiffness of the damper in the displacement and the part related to the damping is the product of the speed multiplied by the damping of the damper [33]. Therefore, the force generated in this system will be in the form of a sine expression with phase difference related to displacement because the sum of the terms sine and cosine is equivalent to the sine expression with phase difference [34]. In addition, if the stress resulting from the division of the shear force on the surface of the viscoelastic material $(A)$ is used instead of force, it can be expressed as

$$
\tau(t)=\tau_{0} \sin (\omega t+\delta)
$$

The amplitude of stress and strain is assumed to be proportional to each other through the viscoelastic linear law [35]. In this case, equation (3) is expanded as equation (6):

$$
\begin{aligned}
\tau(t) & =\gamma_{0} G^{*} \sin (\omega t+\delta) \\
& =\gamma_{0}\left(G^{*} \cos \delta \sin \omega t+G^{*} \sin \delta \cos \omega t\right) . \\
\tau(t) & =\gamma_{0}\left(G^{\prime} \sin \omega t+G^{\prime \prime} \cos \omega t\right), \\
G^{*}= & {\left[G^{\prime 2}+G^{\prime \prime 2}\right]^{1 / 2} . }
\end{aligned}
$$

According to Figure 1, one of the reasons for this issue which indicates the dynamic increase coefficient based on the ratio of excitation frequency to the natural frequency of 


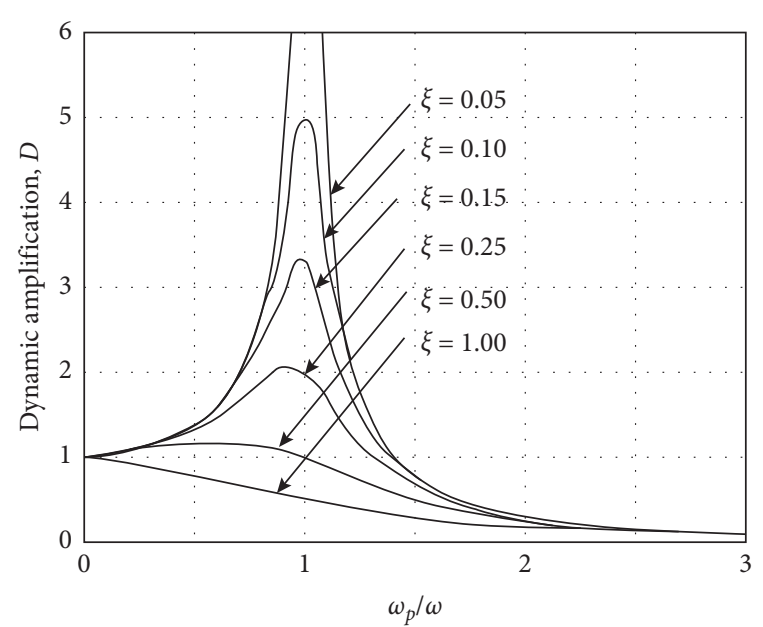

Figure 1: The dynamic increase coefficient based on the load frequency to the natural frequency of the modeling system [36].

the structure is that increased damping is effective only in the main frequency range of the structure which has the greatest effect, and the effect of increasing damping is less effective in other ranges [37]. Therefore, it seems reasonable to consider the main frequency [38].

2.2. Kelvin Model. This model is usually used to model solid viscoelastic materials and the material is modeled as a spring and linear dampers in parallel (Figure 2). In addition, the strain in the spring and damper is equal and the total stress is equal to their total stress as equation (8) [40]:

$$
\begin{aligned}
& \varepsilon=\varepsilon_{1}=\varepsilon_{2}, \\
& \sigma=\sigma_{1}+\sigma_{2} .
\end{aligned}
$$

The hardness and damping values for modeling such materials are obtained from equation (10) [41]:

$$
\begin{aligned}
K_{d} & =\frac{G_{(\omega) \cdot}^{\prime} A}{h}, \\
C_{d} & =\frac{G_{(\omega)}^{\prime \prime} \cdot A}{\omega \cdot h} .
\end{aligned}
$$

In most designs, the distribution of viscoelastic dampers is uniform throughout the building. In addition, the distribution in proportion to the displacement of classes or in proportion to the stiffness of classes is suggested [16].

\section{Numerical Analysis}

3.1. FE Model and Loading. The amount of damage to the floors and frames is compared and a solution to reduce the amount of damage among the members of steel frames with the medium bending frame system is provided. In addition, three steel frames of 4,8 , and 12 floors with the same height of 3 meters were first selected for all floors to evaluate the vulnerability of steel frames based on energy concepts (Figure 3). Then, the lateral loading of each frame was

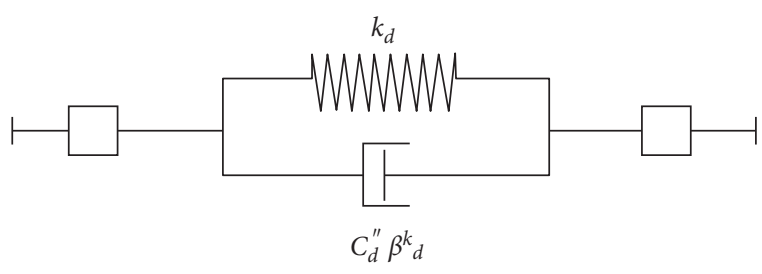

FIgURE 2: The Kelvin analytical model for viscoelastic materials [39].

performed in the same conditions and implemented according to the criteria stated in the building design regulations against earthquakes in a statically equivalent way. The design of the frames was performed by the allowable stress method, relying on the equal resistance distribution in the floors. Then, they were subjected to seven scale-accelerated earthquake-mapped accelerometers.

In addition, a viscoelastic damper is added to the initial bending frame in the middle openings of the frame in all classes for reinforcement. The total dead load plus 20\% live load is considered as a mass to analyze the time history of structures. The Perform3D software uses the relative energy method to calculate kinetic, damping, elastic, and hysteresis energies. Then, the sum of the above energies as input energy is considered. In all stages of nonlinear analysis of frames in Perform3D software, the $P-\Delta$ effect is considered. It is necessary to select earthquake records to perform nonlinear dynamic analysis of time history. Therefore, seven field earthquake records of seven remote field earthquakes have been selected and converted into design earthquakes and then applied to frames. Table 1 displays relatively complete specifications of such records under distant field earthquakes.

Since the viscoelastic damper and its design method discussed before, the steps of the design method of such damper and how to model it in Perform3D software are explained in this section. In this research, the Kelvin mathematical model has been used as a spring and parallel damper to model the viscoelastic damper. In addition, the dampers are designed and their properties are determined according to the frequency of the structure in the state of the structure without dampers and assuming an ambient temperature of $24^{\circ} \mathrm{C}$ and a strain of $20 \%$ (one-third of the maximum strain created in the damper) and assuming damping $15 \%$. Thus, the shear storage modulus and shear loss modulus were first determined by the following diagrams based on the frequency of the structure in the damped state based on Soong's studies and his design method (Figure 4).

In this study, $\eta=1.1$ as $G^{\prime}$ and $G^{\prime \prime}$ are determined; the damper area is calculated by the equations presented in Chapter Two. In addition, the thickness of the damper is determined from the maximum allowable deformation of the damper, which was calculated to be $3.74 \mathrm{~cm}$. It is worth noting that the stiffness of the dampers was determined by the ratio of the stiffness of each class, which are given in Tables 2-4. 


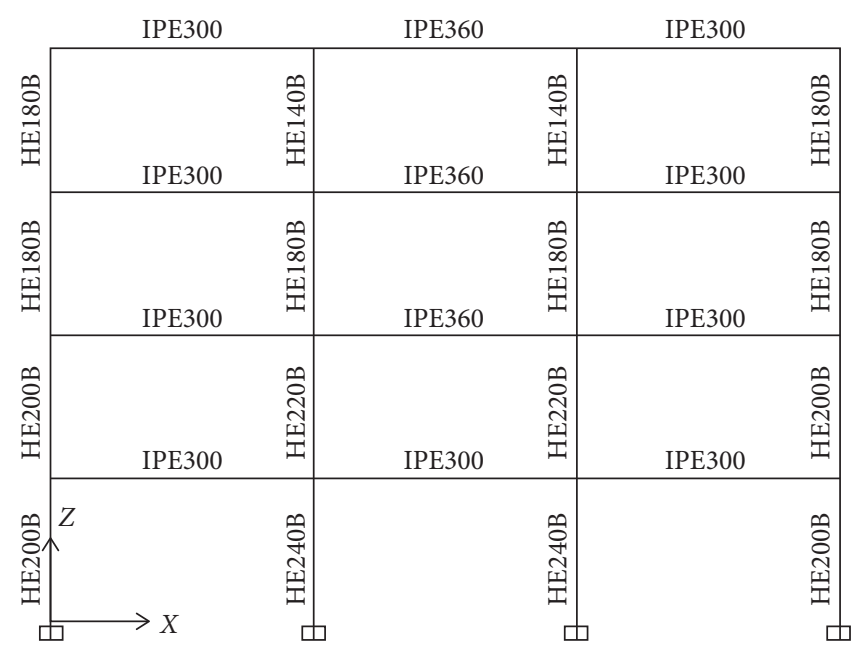

(a)

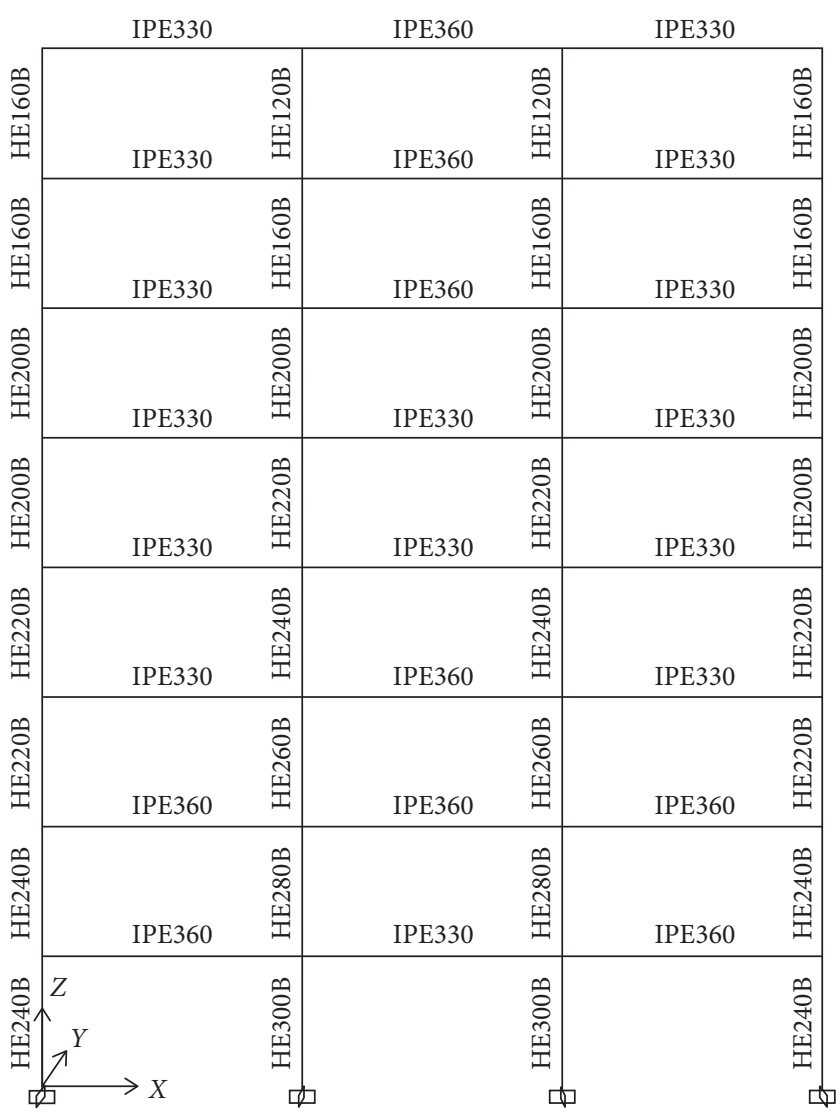

(b)

Figure 3: Continued. 


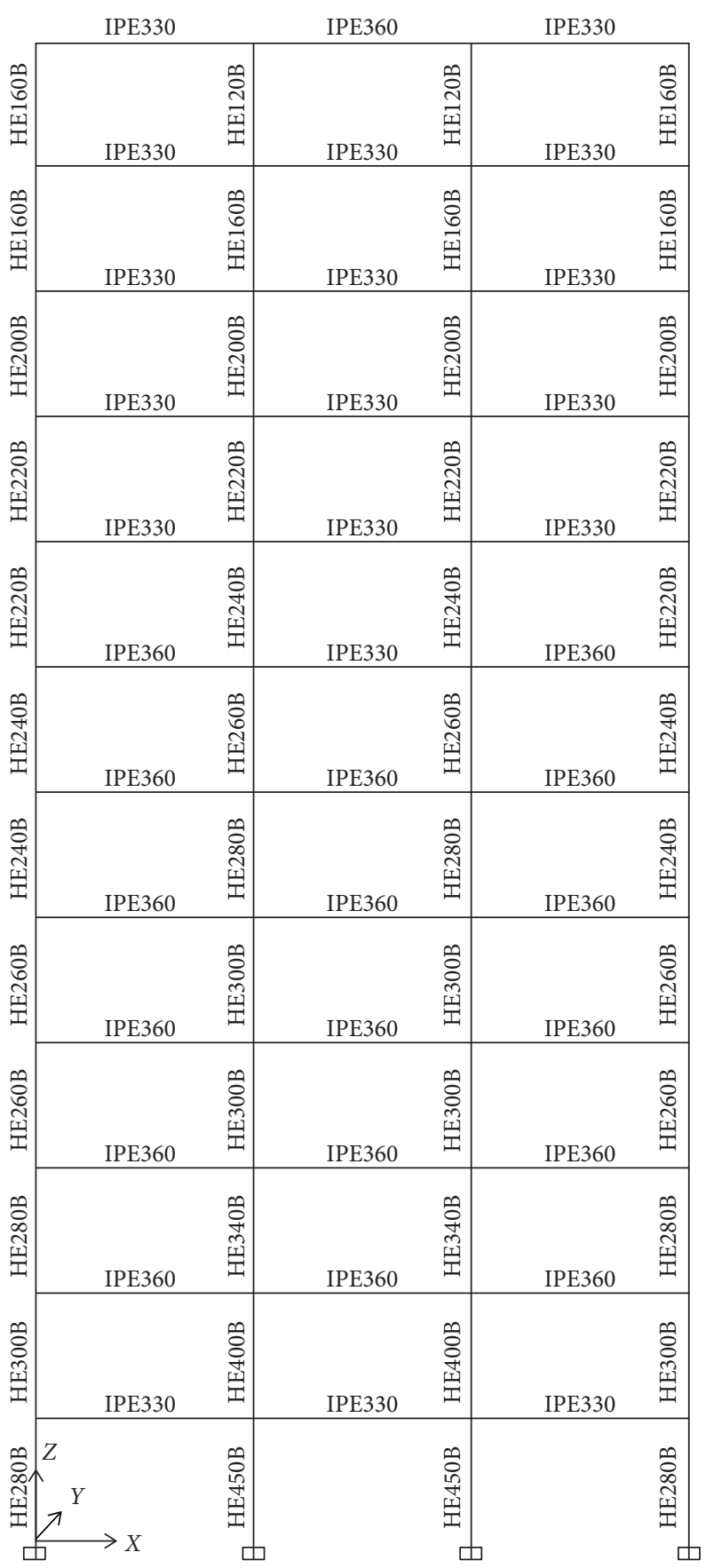

(c)

FIgURE 3: The specifications of (a) 4, (b) 8, and (c) 12-story frame sections.

3.2. Numerical Verification. The three-story structure previously tested by [42] was modeled through the Kelvin mathematical model in this software to validate the accuracy of viscoelastic damper modeling. As shown in Figure 5, the viscoelastic damper was placed diagonally across all floors. The specifications of the sections used in this structure are mentioned in Table 5.

The viscoelastic damper placed in this structure was designed and tested under the temperature, frequency, strain, lateral displacement, and damping of $28^{\circ} \mathrm{C}, 1.6 \mathrm{~Hz}$,
$60 \%, 0.5 \%$, and $15 \%$, respectively. In addition, the type of viscoelastic material used in this experiment is 3M ISD 110 with shear storage modulus of $G \prime=0.06 \mathrm{kN} / \mathrm{cm}^{2}$ and $\eta=1$. The dimensions of the viscoelastic damper used in this study are mentioned in Table 6.

In addition, the amount of damper's hardness is considered as $3.5 \mathrm{kN} / \mathrm{cm}$. The structure mentioned above was subjected to the $0.5 \mathrm{~g}$ earthquake. The hysteresis curve related to this type of damper is considered as one of the prominent features of viscoelastic dampers. As mentioned in 
TABLE 1: The record characteristics of distant field earthquakes.

\begin{tabular}{|c|c|c|c|c|c|}
\hline Earthquake & Component & Magnitude & PGA (g) & Distance from fault $(\mathrm{km})$ & Year \\
\hline Landers & JOS000 & $M_{S}=7.4$ & 0.274 & 21.2 & 1992.06 .28 \\
\hline Kocaeli & ARC000 & $M_{S}=7.8$ & 0.218 & 17 & 1992.08.17 \\
\hline Imperial Valley & H.VCT075 & $M_{S}=6.9$ & 0.122 & 43.5 & 1979.10 .15 \\
\hline Tabas & BAJ.L1 & $M_{S}=7.4$ & 0.094 & 121.2 & 1978.09.16 \\
\hline Loma Prieta & A3E090 & $M_{S}=7.1$ & 0.084 & 57 & 1989.10 .18 \\
\hline Parkfield & C12320 & $M_{S}=6.1$ & 0.063 & 17.3 & 1969.06 .28 \\
\hline San Fernando & WTW025 & $M_{S}=6.6$ & 0.061 & 60.7 & 1971.02.09 \\
\hline
\end{tabular}

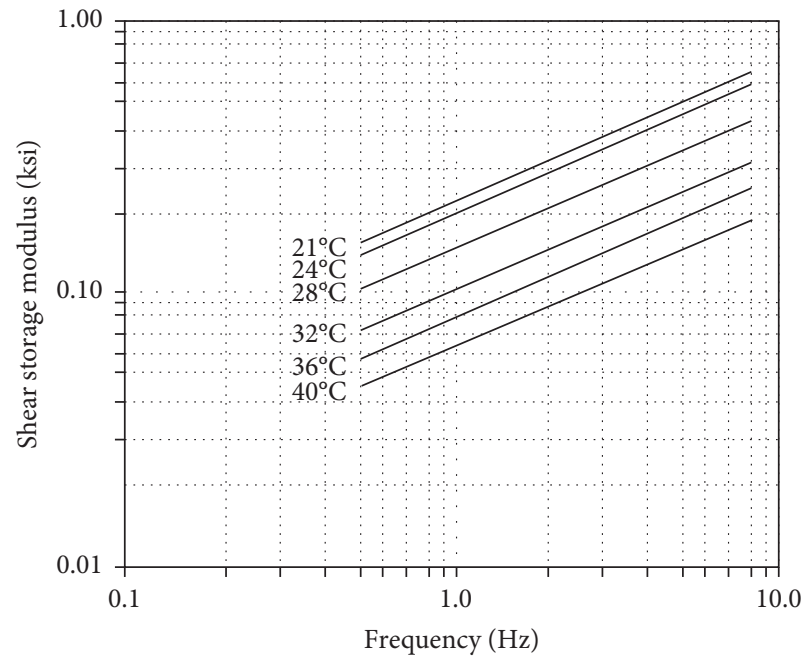

(a)

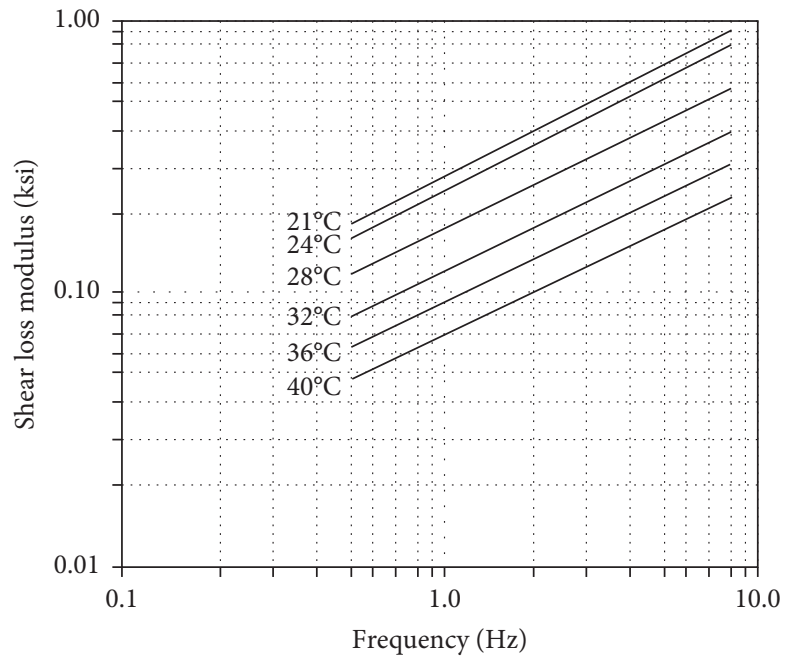

(b)

FIgURE 4: The shear storage and loss modulus based on the frequency [13].

TABle 2: The hardness and damping information of viscoelastic dampers in 4-stage frame.

\begin{tabular}{lcccc}
\hline Floor number & 1 & 2 & 3 & 4 \\
\hline Hardness $(\mathrm{kg} / \mathrm{cm})$ & 10833.4 & 7265.9 & 4818.9 & 3241 \\
Damping $(\mathrm{kg} \cdot \mathrm{s} / \mathrm{cm})$ & 2388.5 & 1594.6 & 1057.6 & 711.3 \\
\hline
\end{tabular}

TABLE 3: Hardness and damping information of viscoelastic dampers in 8-level frame.

\begin{tabular}{lcccccccc}
\hline Floor number & 1 & 2 & 3 & 4 & 5 & 6 & 7 & 8 \\
\hline Hardness $(\mathrm{kg} / \mathrm{cm})$ & 23672.7 & 14889.8 & 12378.3 & 10483.6 & 8519.1 & 7434.1 & 4210.6 & 3151.5 \\
Damping $(\mathrm{kg} \cdot \mathrm{s} / \mathrm{cm})$ & 8295.2 & 5217.6 & 4337.5 & 3673.6 & 298.2 & 2605 & 147.5 & 110.3 \\
\hline
\end{tabular}

TABLE 4: Hardness and damping information of viscoelastic dampers in 12-story frame.

\begin{tabular}{|c|c|c|c|c|c|}
\hline Floor number & Hardness $(\mathrm{kg} / \mathrm{cm})$ & Damping $(\mathrm{kg} \cdot \mathrm{s} / \mathrm{cm})$ & Floor number & Hardness $(\mathrm{kg} / \mathrm{cm})$ & Damping $(\mathrm{kg} \cdot \mathrm{s} / \mathrm{cm})$ \\
\hline 1 & 28.5 & 44.2 & 7 & 5.1 & 97.6 \\
\hline 2 & 57.2 & 3.1 & 8 & 83.1 & 69.5 \\
\hline 3 & 5.2 & 13.9 & 9 & 94.9 & 37.4 \\
\hline 4 & 3.2 & 35.8 & 10 & 55.8 & 78.3 \\
\hline 5 & 2.2 & 89.8 & 11 & 6.5 & 31.2 \\
\hline 6 & 18.2 & 11.7 & 12 & 5.3 & 64.2 \\
\hline
\end{tabular}




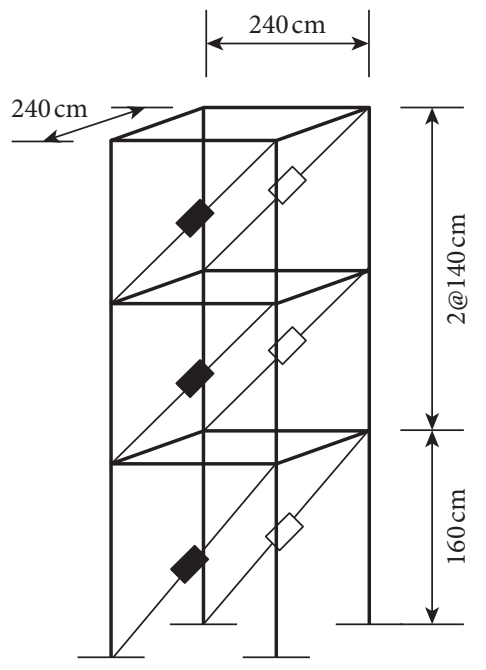

Figure 5: The dimensions and size of the building under test [42].

TABLE 5: The specifications of the sections of the elements [42].

\begin{tabular}{lccccc}
\hline Parameter & \multicolumn{3}{c}{ Beam } & \multicolumn{2}{c}{ Column } \\
& $1^{\text {st }}$ floor & $2^{\text {nd }}$ floor & $3^{\text {rd }}$ floor & $1^{\text {st }}$ floor & $2^{\text {nd }}$ floor \\
\hline Area $\left(\mathrm{cm}^{2}\right)$ & 7 & 6.85 & 6.1 & 9.1 & 7.6 \\
Moment of inertia $\left(\mathrm{cm}^{4}\right)$ & 135 & 122 & 64.9 & 107 & 86 \\
Bending anchor $\left(\mathrm{cm}^{3}\right)$ & 28.5 & 26.8 & 18.7 & 29.9 & 86 \\
\hline
\end{tabular}

TABLE 6: The dimensions and size of the viscoelastic damper [42].

\begin{tabular}{lcc}
\hline Type of damper & Area $\left(\mathrm{cm}^{2}\right)$ & Thickness $(\mathrm{cm})$ \\
\hline Viscoelastic & 8.38 & 3.1 \\
\hline
\end{tabular}

chapter two, this type of curve consists of combined curves of the viscous part, which is horizontal oval, and the elastic part, which is linear, and finally, the hysteresis curve of the viscoelastic damper is elliptical. The hysteresis curve of this damper was investigated to validate the modeling of viscoelastic dampers in Perform3D software. The following hysteresis curve was obtained from the Chang experiment on the structure above under the El Centro earthquake (Figure 6). The shape of the hysteresis curve resulting from modeling is illustrated in Figure 7.

Examining the hysteresis curves related to the Chang experiment and the hysteresis curve resulting from modeling in Perform3D software indicated that the hysteresis curve obtained from the modeling and the curve obtained from the experiment are very similar and the periods of rotation and load are very close to each other. Therefore, the accuracy of viscoelastic damper modeling was proved by Perform3D.

\section{Results and Discussion}

4.1. The Relative Floors Displacement. The results of relative displacement of floors for all frames of 4, 8, and 12 floors were calculated. In addition, the diagram of maximum relative displacement in altitude for different earthquakes

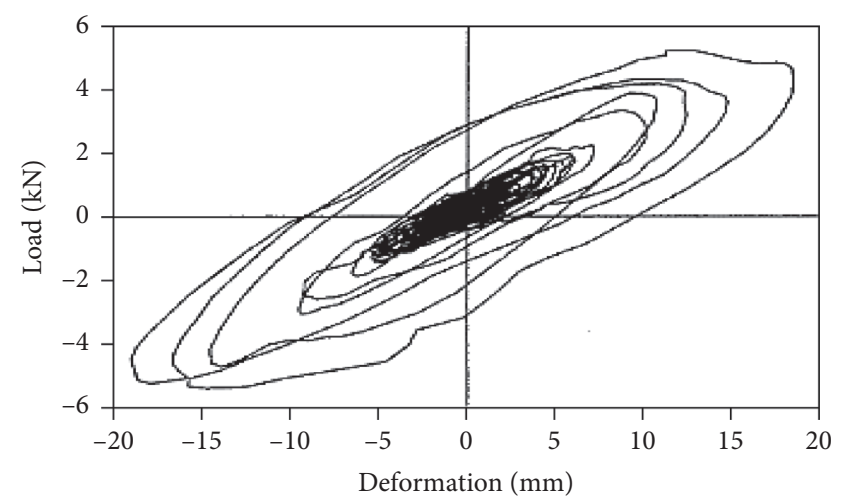

Figure 6: Curve of viscoelastic damping hysteresis under the El Centro earthquake [42].

around the fault is shown. According to the rotation time of the studied frames, being equal to $1.09,1.8$, and 2.3 seconds for 4-, 8-, and 12-floor frames, respectively, the actual relative lateral displacement of the design at the center of mass for buildings with a major periodicity greater than or equal to 0.7 seconds shall not exceed the floor height of 0.02 [43]. Figure 8 shows the maximum relative displacement of the 4story frame below the far-field records in damped and nondamped modes, respectively. Figure 8 indicates that the mean relative displacement of the floors under the seven accelerometers of the remote area is within the permissible limits of the regulations; however, since the restrictions of 


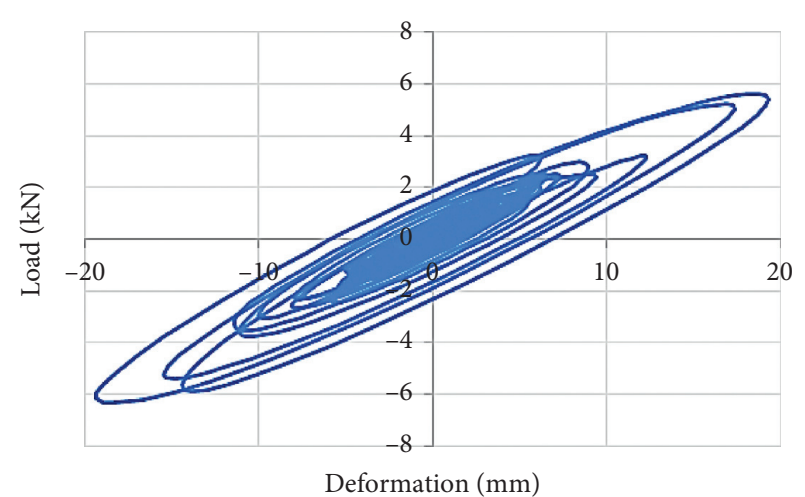

Figure 7: The hysteresis curve resulting from modeling in Perform3D.

the regulations have not been observed under the two records of Lomaprita and Landers, the results after attenuation with dampers were also reviewed. As shown in Figure 8, the mean relative displacement of the floors has decreased significantly and is within the allowable range under all earthquakes.

Figure 9 shows the maximum relative displacement of the 8-story frame under the far-field records, in damped and nondamped conditions. The results of relative displacement for distant seismic earthquakes in Figure 9 indicate that such values on average for classes 7 and 8 exceeded the allowable range of the regulations. Additionally, since it is not within the allowable range for other classes under the Lomaprita and Landers earthquakes, the dampers were added to all classes for retrofitting, in which the results indicate a large decrease.

Figure 10 shows the maximum relative displacement of the 12-story frame below the far-field records, in nondamped and damped conditions. The results of relative displacement for distant earthquakes in Figure 10 indicate that such values were on average within the permissible limits of the regulations, except in the $12^{\text {th }}$ floor. However, since the allowable range has been exceeded for other classes under the earthquakes of Lomaprita, Landers, and Tabas, the dampers have been added to all classes for reinforcement, indicating a large decrease.

\subsection{The Seismic Input Energy considering Tabas Earthquake.} The input energy of the structure under each earthquake is partly lost due to damping and nonlinear behavior (hysteresis energy) and the rest is absorbed in the structure in the form of kinetic energies and elastic strain, which is finally lost by the dampers after the earthquake. For example, the results of the analysis of the input energy in different terms, under the Landers and Tabas records before and after the damping was added to the structure under distant field earthquakes for all frames are shown in Figures 11 and 12. Not all cases were mentioned due to the duplication of descriptions of time history forms related to other earthquakes. The results of the time history of the energy input of the 4-story frame under the earthquake around Tabas before and after the addition of a viscoelastic damper to the frame are shown in Figure 11. As shown in Figure 11, the contribution of hysteresis energy applied to the frame due to the earthquake of the far field is very small (Figure 11). Further, the amount of hysteresis energy and consequently the damage to the structure are reduced and the amount of hysteresis energy reaches almost zero.

Figure 13 shows the results of the time history of the energy input of the 8-story frame under the earthquake around Tabas before and after the addition of the viscoelastic damper to the frame. Similar to the 4-story framework, the contribution of hysteresis energy in the total input energy is low. In addition, adding a damper to the frame leads to absorbing a large portion of the energy by the damper and reducing the amount of hysteresis energy, which is directly related to structural damage.

Figure 12 shows the results of the time history of the energy input of the 12-story frame under the earthquake around Tabas, before and after adding the viscoelastic dampers to the frame. The description of this section is similar to the one provided for the 8-story frame, observing that, as the height of the structure increases, the contribution of hysteresis energy in the input energy increases under farfield records, leading to a decrease by adding a damper to the structure.

\subsection{The Damage Distribution in the Height of the Study} Frames. After examining the energy in the previous sections, this section examines the damage index at the height of the study frame. It is worth noting that the park-stigma damage relationship was used in calculating the damage index [44]. Then, the results related to the 4-, 8-, and 12-floor frames under the far-field records in damped and nondamped conditions are presented as diagrams for comparison. Figure 14 shows the values of the damage index related to the 4-story frame floors below the far-field records in the conditions without dampers and with dampers, respectively. The damage index values are greatly reduced by adding a damper to the floors.

Figure 15 shows the damage index values for the 8-story frame floors below the far-field records in damped and nondamped conditions. As shown, the greatest damage under distant earthquakes is related to the Lomaprita and Landers earthquakes, which occur in floors 2 to 6 , respectively. In addition, it is observed that the damage index values are greatly reduced through adding a damper to the floors.

Figure 16 shows the damage index values for the 12-story frame floors below the far-field records in damped and nondamped conditions. As shown, the greatest damage under distant earthquakes is related to the Lomaprita and Landers earthquakes, which occur in floors 2 to 11, respectively. In addition, it is observed that the damage index values are greatly reduced through adding a damper to the floors.

4.4. The Roof Displacement. The maximum displacement of the roof in centimetres under distant field earthquakes in damped and nondamped conditions is shown in Table 7, 


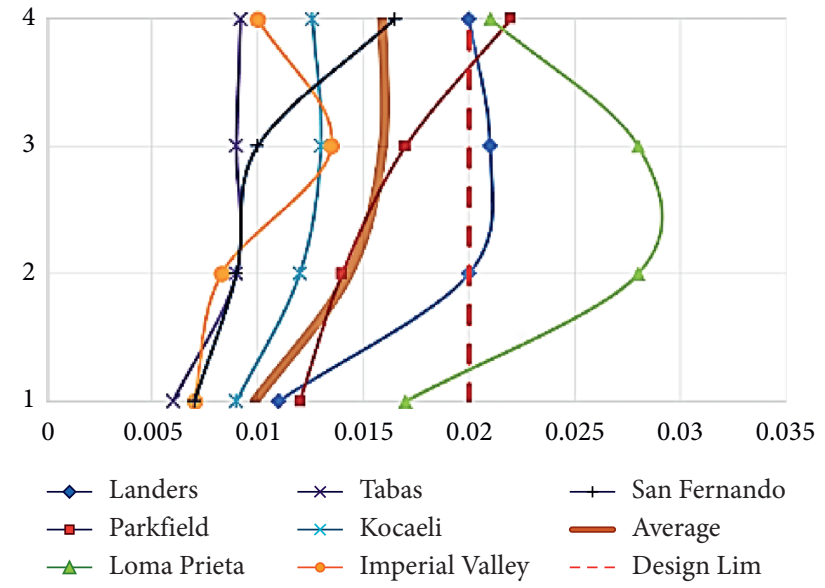

(a)
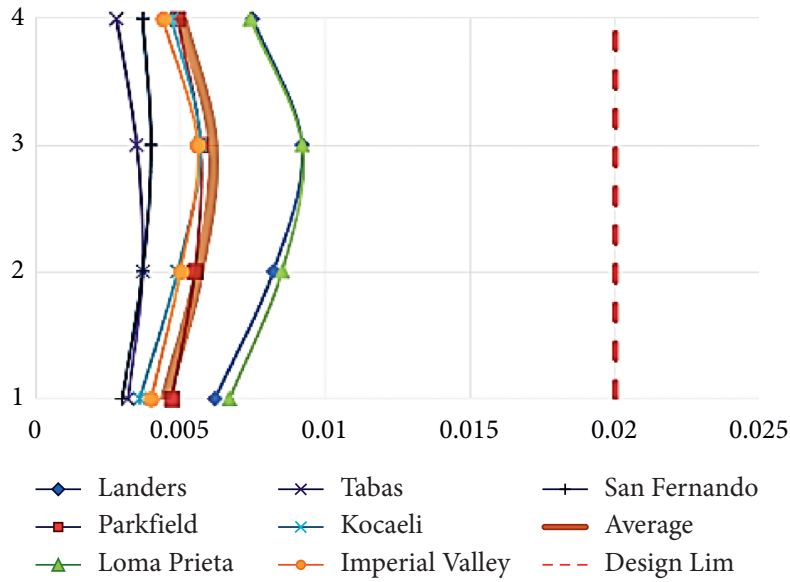

(b)

FIGURE 8: The results of relative displacement of floors in a 4-story frame under damp area records without and with dampers.

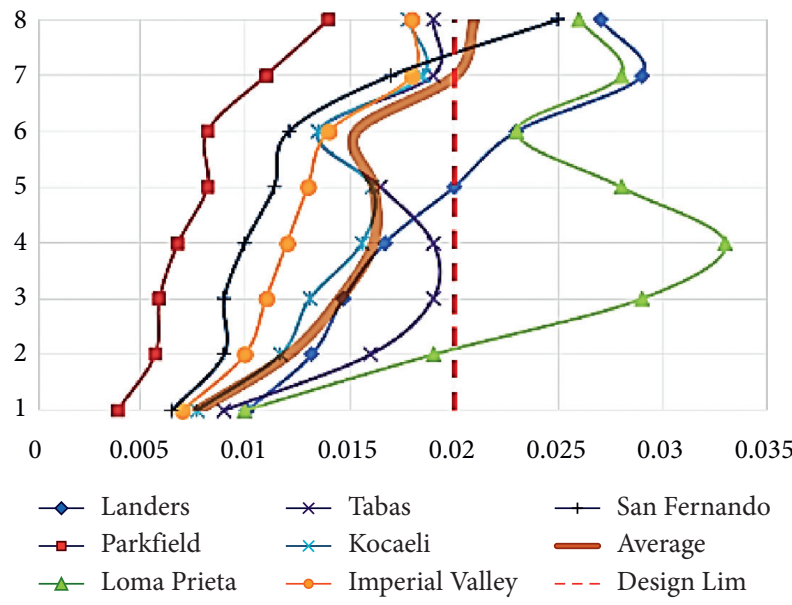

(a)

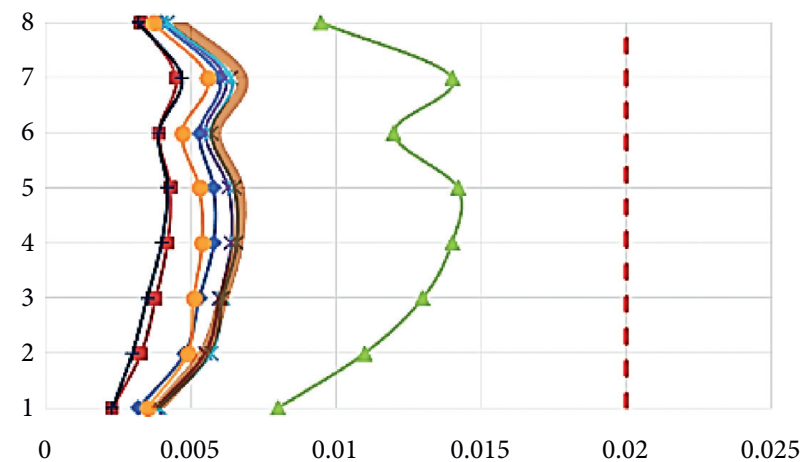

$\begin{array}{lll}\rightarrow \text { Landers } & \rightarrow \text { Tabas } & \rightarrow \text { San Fernando } \\ \rightarrow-\text { Parkfield } & \rightarrow \text { Kocaeli } & \longrightarrow \text { Average } \\ \triangleleft \text { Loma Prieta } & \rightarrow \text { Imperial Valley } & -- \text { Design Lim }\end{array}$

(b)

FIgURE 9: The results of relative displacement of floors in an 8-story frame under damp area records without and with dampers.

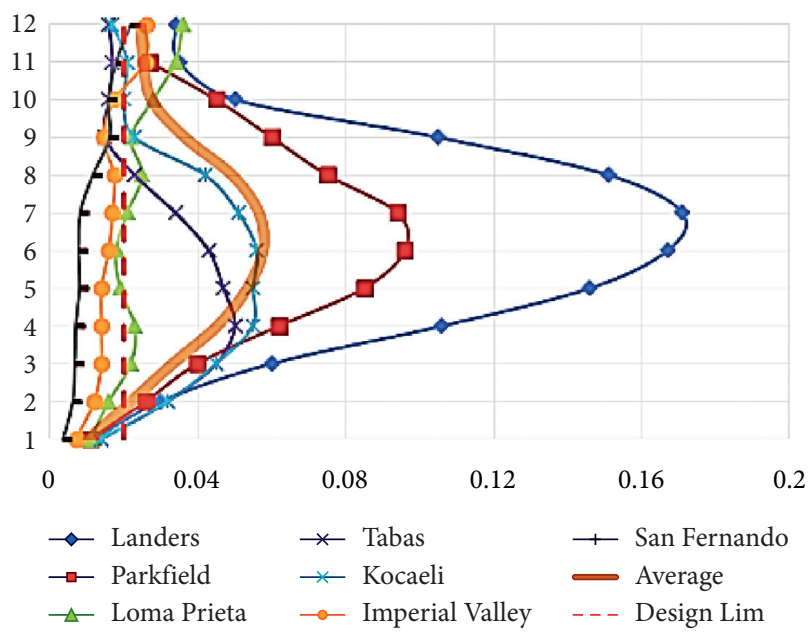

(a)

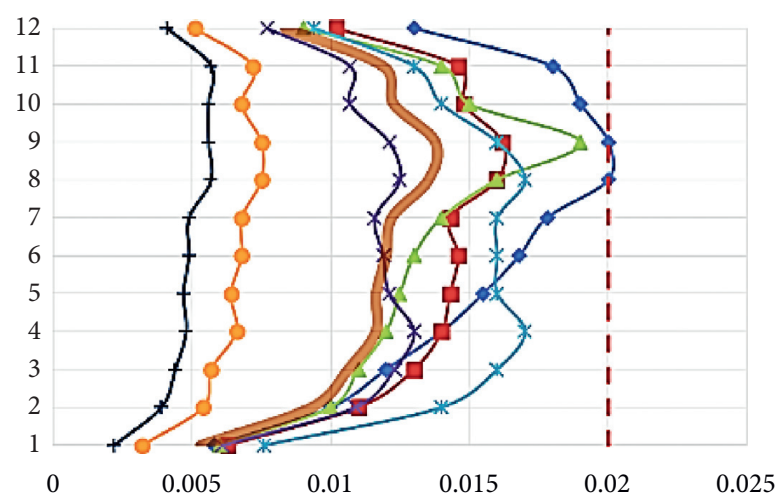

$$
\begin{aligned}
& \multimap \text { Landers } \quad \rightarrow \text { Tabas } \quad+\text { San Fernando } \\
& \rightarrow \text { Parkfield } \rightarrow \leftarrow \text { Kocaeli } \quad \longrightarrow \text { Average } \\
& \neg \text { Loma Prieta } \multimap-\text { Imperial Valley }-\_ \text {Design Lim }
\end{aligned}
$$

(b)

Figure 10: The results of relative displacement of floors in a 12-story frame under far-field records without and with dampers. 


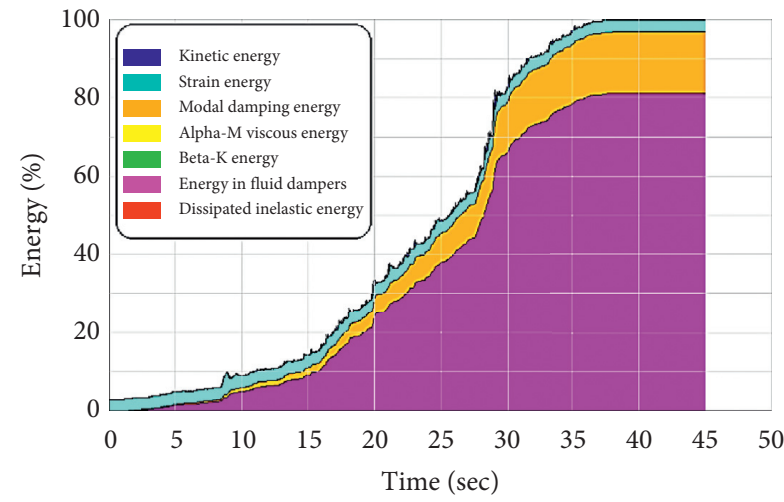

(a)

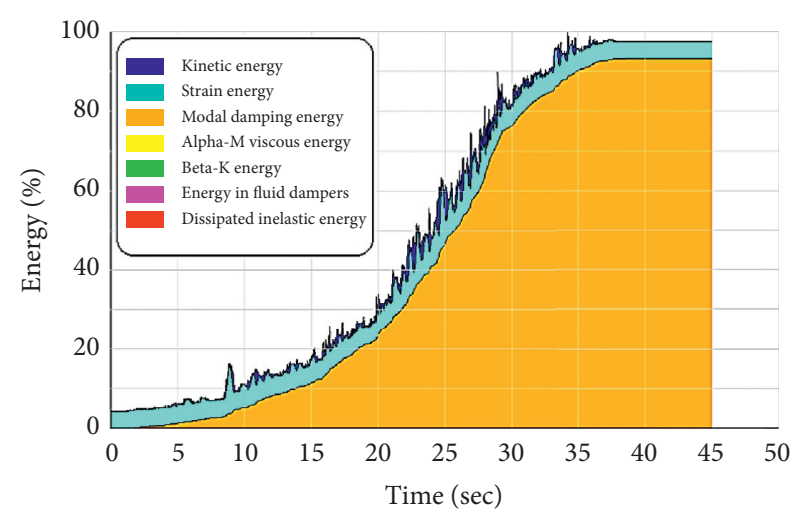

(b)

FIGURE 11: Four-story frame under the record of Tabas with and without damper.

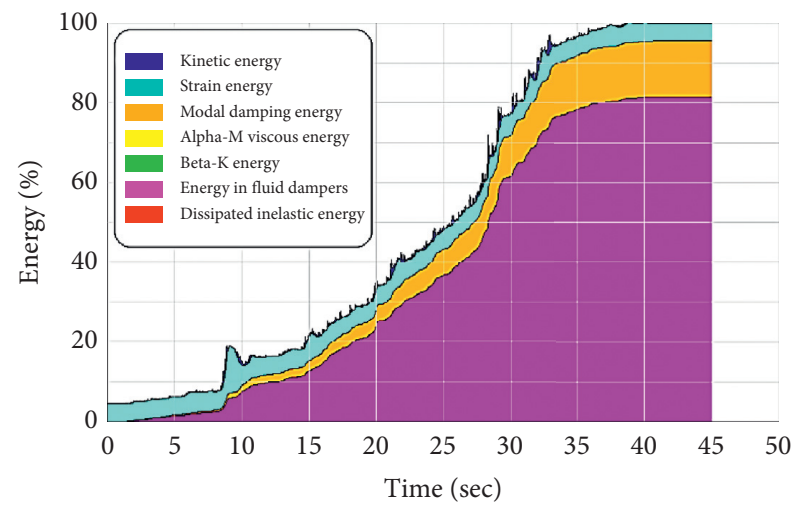

(a)

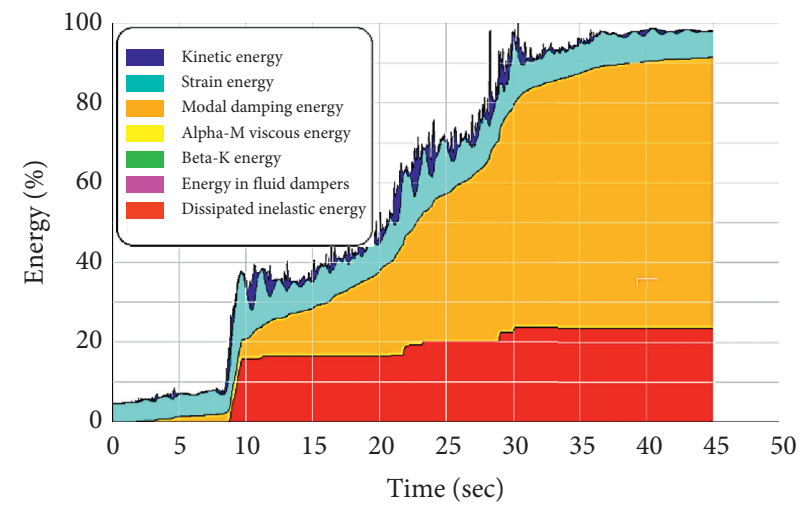

(b)

FIGURE 12: 12-story frame under the record of Tabas with and without damper.

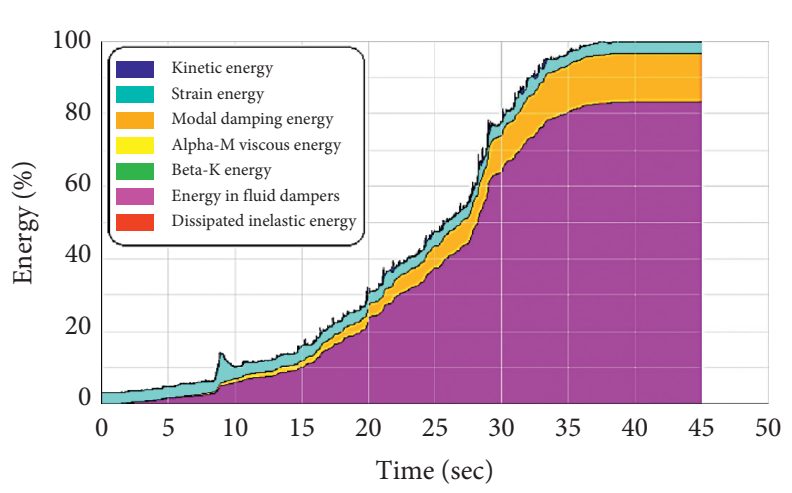

(a)

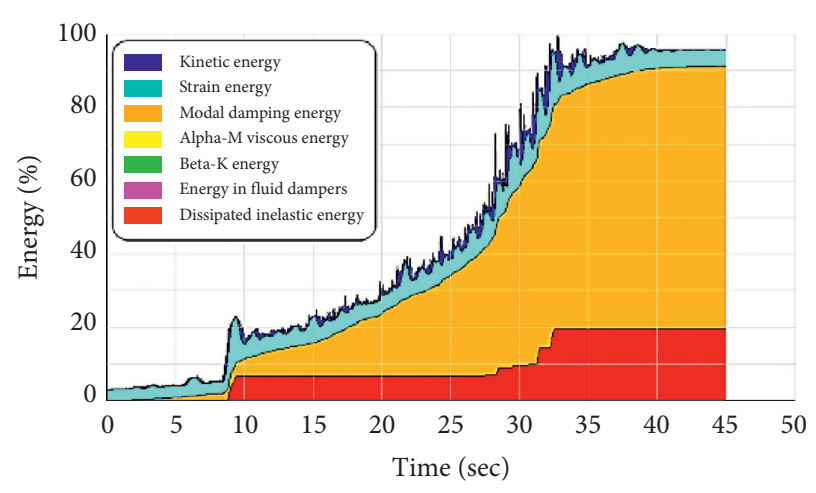

(b)

FIgURE 13: Eight-story frame under the record of Tabas with and without damper.

respectively. In addition, the base shear values increase as the height of the structure increases. The base shear values are greatly reduced through adding dampers to the structural layers, so that $54 \%, 45 \%$, and $48 \%$ reduction are observed for 4-, 8-, and 12-floor frames under remote area earthquakes, respectively. 


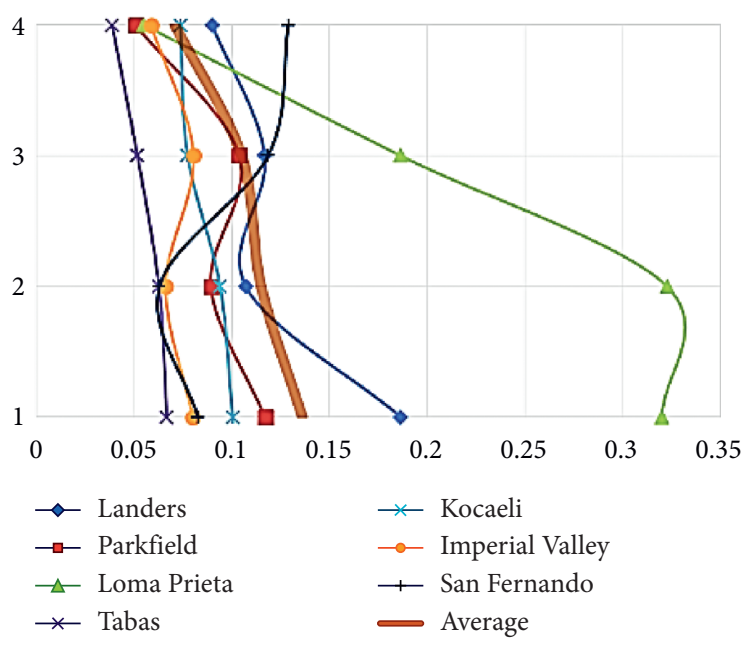

(a)

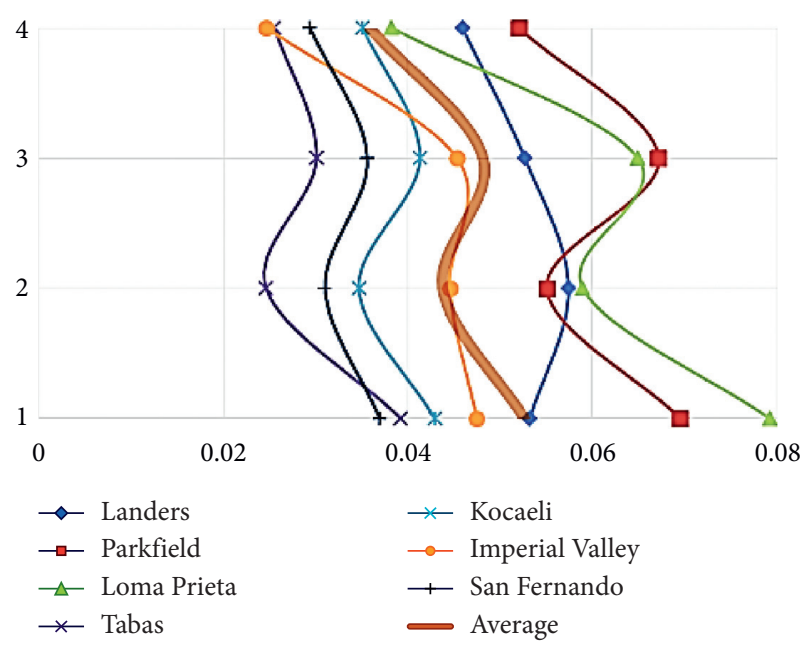

(b)

FIGURE 14: The results of damage distribution in 4-story frame floors under distant field records without and with damper.

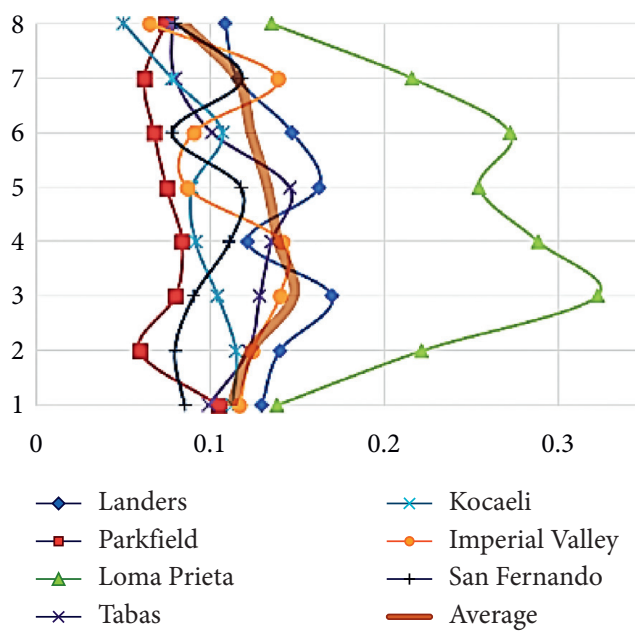

(a)

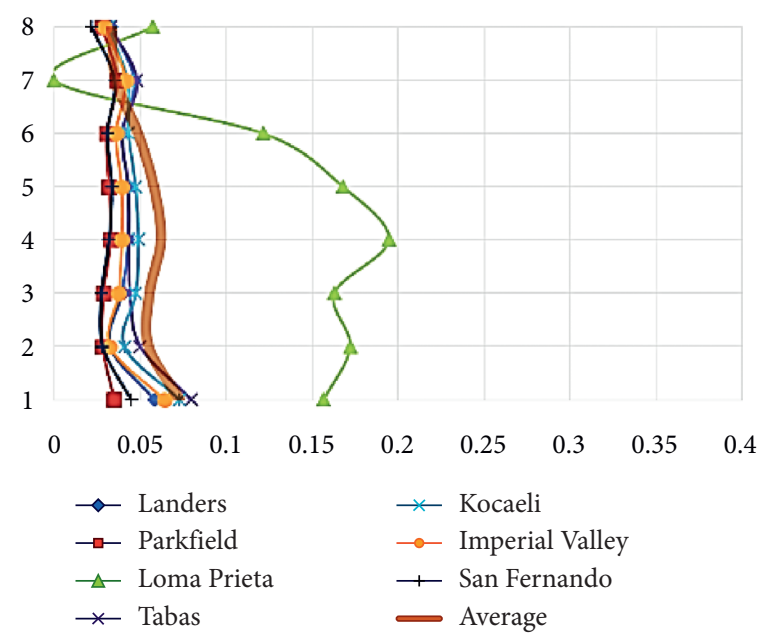

(b)

Figure 15: The results of damage distribution in 8-story frame floors under distant field records without and with damper.

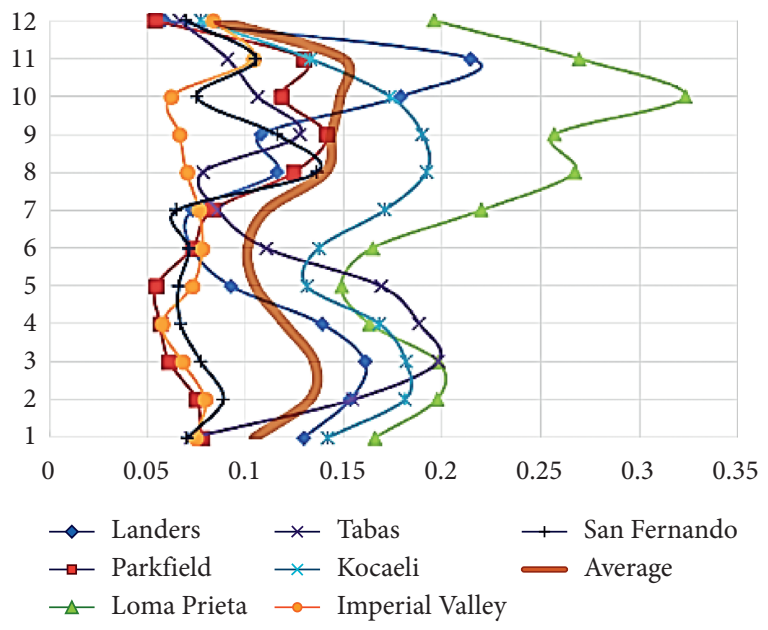

(a)

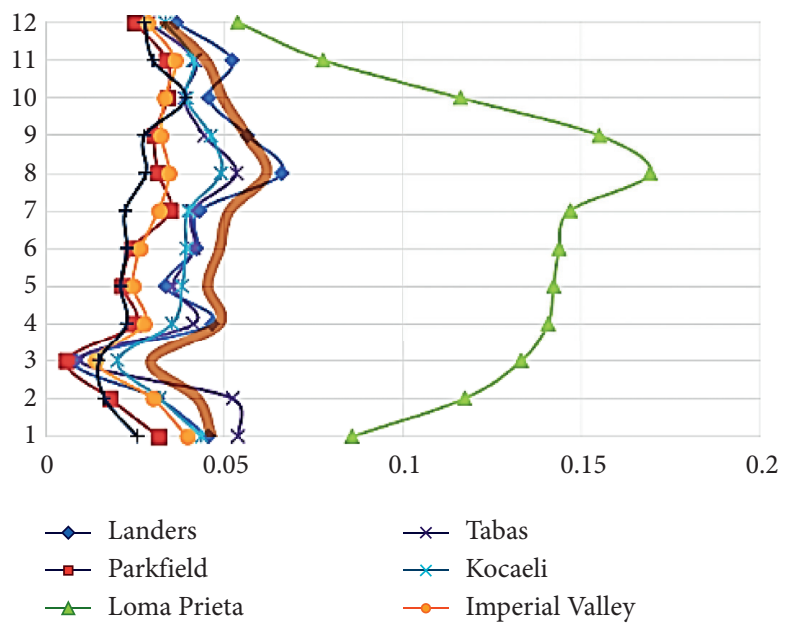

(b)

FIGURE 16: The results of damage distribution in 12-story frame floors under distant field records without and with damper. 
TABLE 7: Roof displacement values in centimetres for remote area records.

\begin{tabular}{lcccccc}
\hline \multirow{2}{*}{ Earthquake } & \multicolumn{2}{c}{ 4-story frame } & \multicolumn{2}{c}{ 8-story frame } & \multicolumn{2}{c}{ 12-story frame } \\
& Without damper & With damper & Without damper & With damper & Without damper & With damper \\
\hline Landers & 17.4 & 9.24 & 49.9 & 16 & 43.2 & 20.9 \\
Parkfield & 20.4 & 10.3 & 64 & 48 & 30 & 39.6 \\
Loma Prieta & 27.6 & 8.4 & 59.5 & 35.2 & 16.7 & 43.6 \\
Tabas & 8.28 & 3.84 & 30.4 & 17.92 & 36.4 & 18.7 \\
Kocaeli & 12 & 5.52 & 37.4 & 13.8 & 19.8 & 19.1 \\
Imperial Valley & 8.88 & 5.4 & 29.4 & 11.2 & 13.7 \\
San Fernando & 8.28 & 4.08 & 21.1 & 8.28 \\
\hline
\end{tabular}

\section{Conclusion}

Controlling the values related to the relative displacement of the floors according to the regulations resulted in exceeding the values from the allowable limits of the regulations. Therefore, the middle opening of all the floors of the studied frames is equipped with viscoelastic dampers to strengthen the above frames. Then, controlling the relative displacement values of the floors indicated that adding dampers to the structure greatly reduces the relative displacement. Then, the results obtained from parametric studies on the studied frames under far-field records were compared with dampers and without dampers in two cases. As the number of layers in the frames increases, the hysteresis energy also increases. The amount of hysteresis energy absorbed by far-field earthquakes is great. Adding viscoelastic dampers to the frames causes a large part of the input energy to be absorbed by the dampers and greatly reduces the hysteresis energy. The structural damage is greatly reduced due to the fact that hysteresis energy is directly related to damage. Examining the base cut in the studied frames indicated that, as the number of floors increases, the amount of base cut increases. Adding a viscoelastic damper to the frames greatly reduces the amount of base shear, and this reduction is low for farfield earthquakes. Comparing the amount of roof displacement before and after the addition of dampers to the structure indicated that the dampers have significantly reduced the amount of roof displacement, which is on average more for distant earthquakes.

\section{Data Availability}

Requests for access to these data should be made to the corresponding author at https://yaserparvin@yahoo.com.

\section{Conflicts of Interest}

The authors declare that there are no conflicts of interest regarding the publication of this paper.

\section{References}

[1] K.-S. Lee, C.-P. Fan, R. Sause, and J. Ricles, "Simplified design procedure for frame buildings with viscoelastic or elastomeric structural dampers," Earthquake Engineering \& Structural Dynamics, vol. 34, no. 10, pp. 1271-1284, 2005.

[2] G. G. Hart, "Earthquake forces for the lateral force code," The Structural Design of Tall Buildings, vol. 9, pp. 49-64, 2000.
[3] A. K. Chopra and E. F. Cruz, "Evaluation of building code formulas for earthquake forces," Journal of Structural Engineering, vol. 112, no. 8, pp. 1881-1899, 1986.

[4] H. Banon and D. Veneziano, "Seismic safety of reinforced concrete members and structures," Earthquake Engineering \& Structural Dynamics, vol. 10, no. 2, pp. 179-193, 1982.

[5] H.-N. Li and G. Li, "Experimental study of structure with "dual function" metallic dampers," Engineering Structures, vol. 29, no. 8, pp. 1917-1928, 2007.

[6] S. Gong and Y. Zhou, "Experimental study and numerical simulation on a new type of viscoelastic damper with strong nonlinear characteristics," Structural Control and Health Monitoring, vol. 24, no. 4, p. 1897, 2017.

[7] H. Banon, J. M. Biggs, and H. M. Irvine, "Seismic damage of reinforced concrete frames," Journal of the Structural Division, vol. 107, no. 9, pp. 1713-1729, 1981.

[8] K. C. Chang, M. L. Lai, T. T. Soong, S. T. Oh, D. S. Hao, and Y. C. Yeh, "Seismic behavior and design guidelines for steel structure with added viscoelastic damper," Technical Report NCEER-93-0009, State University of New York at Buffalo, Buffalo, NY, USA, 1993.

[9] S. Gong, Y. Zhou, and P. Ge, "Seismic analysis for tall and irregular temple buildings: a case study of strong nonlinear viscoelastic dampers," The Structural Design of Tall and Special Buildings, vol. 26, no. 7, p. 1352, 2016.

[10] M. Jamal Shannag and M. Higazey, "Strengthening and repair of a precast reinforced concrete residential building," Civil Engineering Journal, vol. 6, no. 12, pp. 1-12, 2020.

[11] H. N. Li, L. S. Huo, and G. Song, "Advances in structural control in civil engineering in China," Mathematical Problems in Engineering, vol. 2010, Article ID 936081, 23 pages, 2010.

[12] A. Chopra, Dynamic of Structures Theory and Applications to Earthquake Engineering Second Edition, Prentice-Hall, Hoboken, NJ, USA, 2000.

[13] T. T. Soong and G. F. Dargush, Passive Energy Dissipation Systems in Structural Engineering, Wiley, Hoboken, NJ, USA, 1997.

[14] S. Fahim, B. Mohraz, W. T. Andrew, and M. C. Riley, Passive Energy Dissipation Devices For Seismic Application, National Institute of Standard \& Technology, Gaithersburg, MD, USA, 1996.

[15] S. K. Kunnath, A. M. Reinhorn, and R. F. Lobo, "IDARC version 3: a program for the inelastic damage analysis of $\mathrm{rc}$ structures," Technical Report NCEER-92-0022, State University of New York, Buffalo NY, USA, 1992.

[16] K. Chang, T. T. Soong, S.-T. Oh, and M. L. Lai, "Seismic response of a $2 / 5$ scale steel structure with added viscoelastic dampers," Technical Report NCEER-91-0012, University at Buffalo, Buffalo NY, USA, 1991.

[17] L. P. B. Madsen, D. P. Thambiratnam, D. P. Thambiratnam, and N. J. Perera, "Seismic response of building structures with 
dampers in shear walls," Computers \& Structures, vol. 81, no. 4, pp. 239-253, 2003.

[18] U. Mercado Burciaga, "Sustainability assessment in housing building organizations for the design of strategies against climate change," HighTech and Inovation Journal, vol. 1, no. 4, pp. 1-20, 2020.

[19] S. Tezkan and O. Uluca, Reduction of Earthquake Response Of Plane Frame Buildings By Viscoelastic Dampers, Boagzici University, Istanbul, Turkey, 2003.

[20] K.-W. Min, J. Kim, and S.-H. Lee, "Vibration tests of 5-story steel with viscoelastic dampers," Department of Architectural Engineering, vol. 26, 2004.

[21] G. H. Powell, CSI Perform 3d, User Guide, version 5. Ram international, University of California, Berkeley, CA, USA, 2006.

[22] R. W. Clough and J. Penzein, Dynamic of Structures, Mc GrawHill, New York, NY, USA, 1973.

[23] J.-T. Qu and H.-N. Li, "Study on optimal placement and reasonable number of viscoelastic dampers by improved weight coefficient method," Mathematical Problems in Engineering, vol. 2013, no. 1, 10 pages, Article ID 358709, 2013.

[24] H. Heydarinouri and S. M. Zahrai, "Iterative stepby-step procedure for optimal placement and design of viscoelastic dampers to improve damping ratio," The Structural Design of Tall and Special Buildings, vol. 26, no. 9, p. 1361, 2017.

[25] Y. Ribakov and G. Agranovich, "A method for design of seismic resistant structures with viscoelastic dampers," The Structural Design of Tall and Special Buildings, vol. 20, no. 5, pp. 566-578, 2011.

[26] M. S. L. Roufaiel and C. Meyer, "Analysis of damaged concrete frame buildings," Technical Report NSF-CEE-81-21359-1, Columbia University, New York, NY, USA, 1983.

[27] H. Li, T. Yi, M. Gu, and L. Huo, "Evaluation of earthquakeinduced structural damages by wavelet transform," Progress in Natural Science, vol. 19, no. 4, pp. 461-470, 2009.

[28] H. Akyama, Earthquake -Resistant Limit -State Design For Buildings, The University Of Tokyo Press, Tokyo, Japan, 1985.

[29] C.-M. Uang and V. V. Bertero, "Evaluation of seismic energy in structures," Earthquake Engineering \& Structural Dynamics, vol. 19, no. 1, pp. 77-90, 1990.

[30] Y. J. Park and A. H. S. Ang, "Mechanistic seismic damage model for reinforced concrete," Journal of Structural Engineering, vol. 111, no. 4, pp. 722-739, 1985.

[31] H. Qian, H. N. Li, G. Song, and W. Guo, "Recentering shape memory alloy passive damper for structural vibration control," Mathematical Problems In Engineering, vol. 2013, Article ID 963530, 13 pages, 2013.

[32] F. Weber, G. Feltrin, O. Hath, Guidelines for Structural Control Samco Final Report, Structural Engineering Research Laboratory, Dübendorf, Switzerland, 2006.

[33] Y. Zhou, X. Lu, D. Weng, and R. Zhang, "A practical design method for reinforced concrete structures with viscous dampers," Engineering Structures, vol. 39, pp. 187-198, 2012.

[34] E. DiPasquale and A. S. Cakmak, "Detection of seismic structural damage using parameter-based global damage indices," Probabilistic Engineering Mechanics, vol. 5, no. 2, pp. 60-65, 1990.

[35] K. Whipp, Structural Control By Induced Stress Based Stiffness Modification Thesis, Vanderbilt University, Nashville, TN, USA, 2005.

[36] M. Zimmer, "Characterization of visco-elastic materials for use in seismic energy dissipation systems," Master of Science Thesis, University at Buffalo, Buffalo, NY, USA, 2000.
[37] L. Furgani, M. A. Hariri-Ardebili, M. Meghella, and S. M. Seyed-Kolbadi, "On the dynamic capacity of concrete dams," Infrastructure, vol. 4, no. 3, pp. 57-19, 2019.

[38] Y. Ibrahim, "A new visco-plastic device for seismic protection of structure," Doctor of Philosophy Thesis, Virginia Polytechnic Institute, Blacksburg, VA, USA, 2005.

[39] Z. Yang and E. S. S. Lam, "Dynamic responses of two buildings connected by viscoelastic dampers under bidirectional earthquake excitations," Earthquake Engineering and Engineering Vibration, vol. 13, no. 1, pp. 137-150, 2014.

[40] T. H. Yi, H. N. Li, and H. M. Sun, "Multi-stage structural damage diagnosis method based energy-damage theory," Smart Structures and Systems, vol. 12, no. 3-4, pp. 345-361, 2013.

[41] Y. Zhou, S. M. Gong, and X. L. Lu, "Study on similarity of hysteretic loops and characteristic parameters of viscoelastic dampers with test verifications," Applied Mechanics and Materials, vol. 353-356, pp. 1970-1975, 2013.

[42] K. C. Chang, S. J. Chen, and M. L. Lai, "Inelastic beheavior of steel frames with added viscoelastic dampers," Journal of Structural Engineering, vol. 122, no. 10, 1996.

[43] A. Benavent-Climent, "An energy-based damage model for seismic response of steel structures," Earthquake Engineering \& Structural Dynamics, vol. 36, no. 8, pp. 1049-1064, 2007.

[44] H. Iemura, "Earthquake failure criteria of deteriorating hysteretic structures," in Proceedings of the 7th World Conference of Earthquake Engineering, pp. 8-13, Istanbul, Turkey, September 1980. 